\title{
BACTERIAL IDENTIFICATION BY INFRARED SPECTROPHOTOMETRY ${ }^{1}$
}

\author{
JACKSON W. RIDDLE,? PAUL W. KABLER, BERNARD A. KENNER, \\ ROBERT H. BORDNER, SUE W. ROCKWOOD, AND \\ HEBER J. R. STEVENSON \\ Microbiology Section, Robert A. Taft Sanitary Engineering Center, U. S. P. H. S., \\ Cincinnati, Ohio
}

Received for publication February 17, 1956

The possibilities of identification of biological materials by infrared spectrophotometric methods were first suggested by Coblentz (1911), and by Stair and Coblentz (1935). Since then papers have been published on the chemical components or fractions obtained by chemical means from bacteria by Randall et al., (1951, 1952), Burket and Melvin (1952), Levine and his co-workers (1952, 1953a,b,c), Smith, Harrell, and Randall (1954); and from yeast cells by Simon and Hedrick (1955). Spectra of viruses have been reported by Pollard and his associates (1952) and by Randall and Smith (1953). More recently Benedict (1955) has been able to differentiate four groups of viruses on the basis of their different infrared absorption spectra. Blout and Mellors (1949), Schwarz and his associates (1951, 1952), and Thomas, Austin, and Davies (1954) have all described infrared spectra of tissues, and spectra of mosquito extracts have been used by Micks and Benedict (1953) as a means of identification.

In their publications, Stevenson and Bolduan (1952) and Levine et al. (1953) noted that considerable differences are present in the infrared absorption spectra of various bacteria. Corroborative evidence from England has been presented recently by Thomas and Greenstreet (1954).

Few clear-cut examples of definite chemical interpretation of bacterial infrared absorption bands have been made. According to Levine and his co-workers $(1953 a, b)$, the 6.05 and $6.45 \mu$ bands are largely derived from the peptide linkages of the bacterial protein, and the 8.0 to $8.1 \mu$ band is due to bacterial nucleic acids;

1 This work was performed under contract with the Army Chemical Corps, Fort Detrick, Frederick, Maryland.

2 Present address: Departments of Bacteriology and Preventive Medicine, Ohio State University, Columbus, Ohio. carbohydrates and nucleic acids are largely responsible for the deep band from 8.6 to $10 \mu$. However, because all bacteria studies so far have these same absorption bands, the apparent dissimilarities which have been observed among spectra of microorganisms largely are due to smaller differences in the percentages of infrared transmission and absorption at various wavelengths, and the shapes of absorption maxima and minima.

Therefore, procedures which will permit precise quantitative reproduction of spectra are necessary, in order to obtain the subtle differences which may be significant in identification. Because the differences in microbial infrared spectra, in general, lie in the percentages of transmission and absorption at various wavelengths, instead of in the presence or absence of specific absorption bands, the coding of bacterial spectra for purposes of comparison and identification must be quite unlike the methods used for the coding of infrared absorption and chemical structure data as described by Kuentzel (1951), Martin (1952), and Randall, Fowler, Fuson, and Dangl (1949).

The objectives of this paper are threefold: (1) to present the procedures which have been developed to produce infrared spectra of bacteria with quantitative reproducibility of a very high order, (2) to show that such standard spectra can be coded and transferred to punch cards for electromechanical sortings and comparisons, and (3) to illustrate the differences which exist among infrared spectra of certain bacteria that can be of value in their rapid identification.

\section{MATFRIALS AND METHODS}

Microorganisms. The bacteria used in this investigation represent a diverse sampling from the order Eubacteriales and some species from the order Actinomycetales. The group includes a variety of miscellaneous pathogenic and non- 
TABLE 1

Microorganisms studied by infrared spectrophotometry

\begin{tabular}{|c|c|c|c|}
\hline Genus or Group & 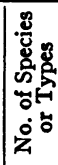 & 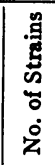 & SEC Medium No. \\
\hline Acetobacter... & 1 & 1 & $\begin{array}{c}101 \text { (Eugonager, } \\
\text { BBL) }\end{array}$ \\
\hline Achromobacter... & 1 & 1 & $\begin{array}{l}99 \text { (Fortified } \\
\text { Tryptose } \\
\text { Agar *4) }\end{array}$ \\
\hline Aerobacter. & 2 & 16 & 99 \\
\hline Agrobacter. & 1 & 1 & 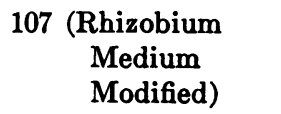 \\
\hline Alcaligenes.. & 2 & 3 & 99 \\
\hline Azotobacter... & 1 & 1 & 99 \\
\hline Bacillus.... & 8 & 26 & 99 \\
\hline Brucella....... & 3 & 22 & 99 \\
\hline Chromobacter... & 1 & 1 & 99 \\
\hline Corynebacterium. & 6 & 11 & $\begin{array}{c}\text { 100A (Trypticase } \\
\text { Soy Agar }+ \\
\text { Dextrose) }\end{array}$ \\
\hline Diplococcus & 4 & 7 & $\begin{array}{c}102 \text { (Brain Heart } \\
\text { Infusion } \\
\text { Agar }+ \\
\text { Hemoglobin) }\end{array}$ \\
\hline Erwinea....... & 1 & 1 & 99 \\
\hline Erysipelothrix & 1 & 12 & $100 \mathrm{~A}$ \\
\hline Escherichia. & 25 & 89 & 99 \\
\hline Flavobacterium. & 2 & 2 & 99 \\
\hline Klebsiella.... & 9 & 37 & 99 \\
\hline Leuconostoc. & 2 & 6 & 101 \\
\hline Listeria...... & 1 & 4 & 101 \\
\hline Micrococcus... & 8 & 19 & 99 \\
\hline Neisseria........ & 1 & 3 & 99 \\
\hline Paracolon......... & 7 & 33 & 99 \\
\hline Paracolobactrum.. & 2 & 20 & 99 \\
\hline Pasteurella........ & 1 & 1 & 99 \\
\hline Proteus........ & 6 & 34 & 99 \\
\hline Pseudomonas. & 11 & 14 & 99 \\
\hline Rhizobium... & 6 & 11 & 107 \\
\hline Salmonella.. & 50 & 214 & 99 \\
\hline Sarcina. & 2 & 2 & 99 \\
\hline Serratia... & 2 & 3 & 99 \\
\hline Shigella.... & 12 & 14 & 99 \\
\hline Streptococcus. & 9 & 28 & $\begin{array}{c}104 \text { (AC-Medium, } \\
\text { Difco) }\end{array}$ \\
\hline Xanthomonas. & 7 & 7 & $\begin{array}{c}65 \text { (Nutrient } \\
\text { Agar, Difco) }\end{array}$ \\
\hline Yeasts. & 6 & 6 & $\begin{array}{c}108 \text { (Phytone Dex- } \\
\text { trose Agar) }\end{array}$ \\
\hline Totals .......33 & 201 & 650 & \\
\hline
\end{tabular}

pathogenic bacteria. They were obtained from the stock culture collections of the Department of Bacteriology, Ohio State University, and the Communicable Disease Center, U. S. Public Health Service, and from various private sources. Identification of each culture was confirmed or established by complete bacteriological and serological studies.

Conditions of cultivation and culture media were kept constant for each microorganism throughout the studies reported here. The various genera, the numbers of species and strains per genus, and the culture media used are listed in table 1.

Procedures for obtaining standard infrared spectra of microorganism. After $18 \mathrm{hr}$ incubation, a portion of the bacterial growth from a culture plate was harvested with a rubber tipped policeman. The bacteria were washed off the policeman by dipping it into a small pyrex tube containing a minimum $(0.25 \mathrm{ml})$ of distilled water and covered with a foil cap. Smears of the contents were made on $\mathrm{AgCl}$ discs which were flat, free of deep scratches in the region penetrated by the infrared beam, and polished to give, when compared with air, infrared transmissivities between 78 and 80 per cent at $5 \mu$.

When handling true or potential pathogens bacterial suspensions were autoclaved before the preparation of the sample film. The bacteria in the dense aqueous suspension were spread evenly over an area of approximately 2 by $2 \mathrm{~cm}$ on the $\mathrm{AgCl}$ disc. The disc was tilted by resting one edge on an applicator stick, and the sample was air-dried in this position. During drying, the disc was tilted back and forth a time or two to obtain a more uniform film. In this way a wedge shaped, variable thickness sample was produced.

The instrument used in this study was a Perkin-Elmer Double Beam Recording Infrared Spectrophotometer, Model 21. Proper functioning and optimal settings of the instrument were assured by recording the infrared spectrum of a standard polystyrene film each week, and by comparing it with such spectra previously obtained. The spectrophotometer was balanced at 0 and 100 per cent transmission at $5 \mu$. Care was taken to insure precise placement of the paper on the drum and accurate alignment of the pen.

The instrument was advanced through the micron range to $8.05 \mu$ and stopped. The disc bearing the dried, variable thickness film was 
placed in the sample beam and manipulated until the transmission through the sample film registered exactly 50 per cent at $8.05 \mu$. The disc was then anchored in this position and the instrument reversed to $5 \mu$. The spectrum was run full scale (one inch per micron), at a speed of $11 / 2 \mathrm{~min}$ per micron, with the gain set at 5, resolution at 927, response at 2-2, and with the following slit width settings: 37 at $5 \mu, 68$ at $8.05 \mu$, and 101 at $10 \mu$.

If transmission at $5 \mu$ was not at least 78 per cent, the film was considered unsatisfactory and was reworked on the disc by adding a drop of distilled water, mixing and respreading the suspension with a rubber tipped policeman, and redrying. The film covered disc was then replaced in the sample beam and adjusted again as above, before the spectrum was obtained.

Flat films which at $8.05 \mu$ gave transmissions ranging from 48 to 54 per cent also were satisfactory for obtaining reproducible spectra; by slight manipulation an area could be found which allowed precisely 50 per cent transmission at that wavelength.

$A$ system for coding and recording bacterial infrared spectra on punch cards. The Hollerithtype (IBM) punched cards used in conjunction with electric sorting machines offered a versatile system for recording and analyzing a large quantity of coded data on a single card with the speed and accuracy of electric sorting.

The only mechanical equipment required by this system was a key punch and sorter. A verifier was useful but not essential.

To incorporate some degree of tolerance to compensate for very small differences in transmission and absorption percentages between strains of the same species, and to facilitate the recording and comparison of cards, sections of each spectrum were adjusted upward or downward when coded, by basing each section at a fixed percentage as follows:

Section A started at $5.6 \mu$ based at 70 per cent

Section B ran from 6 to $7 \mu$ and was based at $6.5 \mu$ at 40 per cent

Section $C$ started at $7.0 \mu$ based at 50 per cent Section D started at $8.0 \mu$ based at 50 per cent Section E started at $9.0 \mu$ based at 50 per cent Section $F$ started at $10.0 \mu$ based at 50 per cent Section $G$ started at $11.0 \mu$ based at 55 per cent

These adjustments only altered slightly the longer vertical passages of the spectrum, and preserved entirely the specific locations and shapes of absorption maxima and minima which were characteristic of the spectrum.

Because the adjustment schedule was based on zones of percentage transmission in each micron, the major portion of a bacterial spectrum will have adjusted transmittances between 50 and 60 per cent; small sections may fall between 50 and 40 per cent, and between 60 and 70 per per cent. Only the portion of a spectrum from 5 to $5.6 \mu$ is likely to be above 70 per cent, and only the portion from 6 to $6.3 \mu$ is likely to be below 40 per cent.

Because the percentage transmission at 5.6, $6.5,7,8,9,10$, and $11.0 \mu$ was arbitrarily fixed for all spectra, it was unnecessary to punch these positions in the card. With the use of $x$ and $y$ overpunches singly or in combination, in addition to the numerals, it was possible to record the percentage transmission at each tenth micron of wavelength in a single column of the punch card. By this method, the entire spectrum from 5.6 to $\mathbf{1 2 . 1} \mu$ could be recorded in $\mathbf{5 8}$ columns.

Columns 59 through 66 were not assigned, and are available for recording special features. Columns 67 and 68 were reserved for recording the serial number of the culture medium used; columns 69 through 71 were used to record the serial numbers of the experiments; column 72 was reserved for recording the gram reaction and the morphology of the microorganism from which the spectrum was obtained. The serial number of the bacterial culture was punched in columns 73 through 76, and the serial number of the individual spectrum was recorded in columns 77 through 80. Codes using the overpunches provide expansion in these fields of the card to accomodate even very large collections.

\section{RESULTS}

Reproducibility of spectra of different samples from the same bacterial strain. Using the techniques of film preparation and spectrophotometer adjustments as presented in the preceding section, infrared spectra of three different samples of the same strain (SEC 67) of Bacillus anthracis were obtained. Tracings of these unadjusted spectra were superimposed and are shown in figure 1. Tracings of similarly obtained spectra from different samples of the same strain (SEC 260) of Neisseria catarrhalis, and of Alcaligenes faecalis (SEC 55) are shown respectively in 


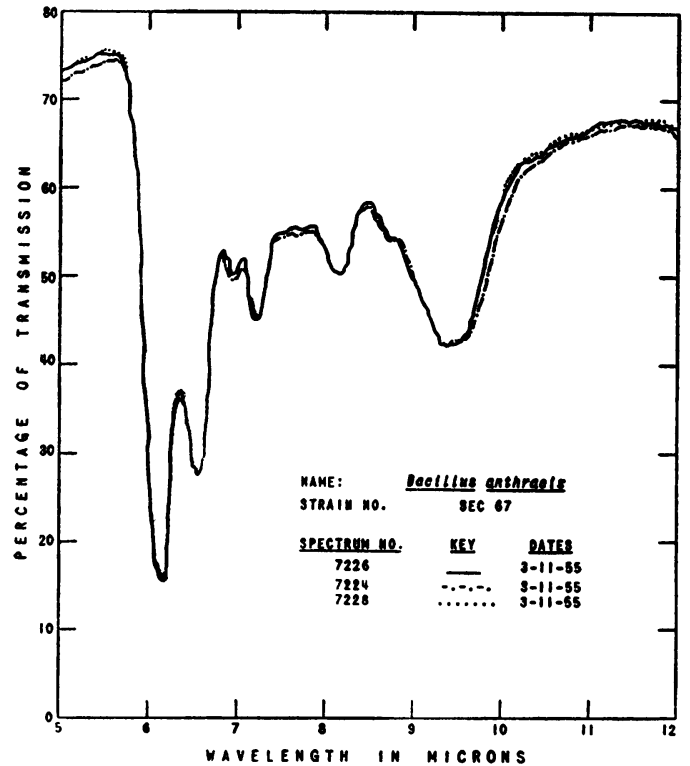

Figure 1

figures 2 and 3 . The dates given in the legends indicate that the time of lapse between some samples varied from the same day to intervals of a week, and in one case (figure 3) a period of six months.

As is evident from examination of these examples of unadjusted spectra of the same bacterial strains, this technique resulted in the production of spectra which were superimposable throughout nearly the complete range from 5.7 to $12.0 \mu$. Variations in reproducibility fell within \pm 136 per cent and were generally confined to absorption maxima and minima, although the wavelengths at which they occurred were unaffected.

Furthermore, it is readily seen by comparing these examples of unadjusted spectra of different bacteria (figures 1 to 3 ), that although they have absorption bands in common, for example at $6.05 \mu, 6.45 \mu, 6.9 \mu, 7.2 \mu$ and $8.1 \mu$, there are obvious differences in spectra which characterize these particular bacterial strains.

Reproducibility of different strains of the same bacterial species. To determine similarities and dissimilarities among strains of species of bacteria, as well as among different species and genera, a total of 1,395 spectra of 650 strains of 201 species were studied. Examples of the degree of reproducibility obtained are shown by the tracings of unadjusted spectra of five different strains of Salmonella typhimurium in figure 4.
Effect of adjustment on infrared spectra of bacteria. Despite the superimposibility of specific spectral contours of different strains of the same species, very small differences in percentages of transmissions and absorption may exist among different strains. In order to incorporate some degree of tolerance to compensate for these small differences, the breaking of each spectrum into

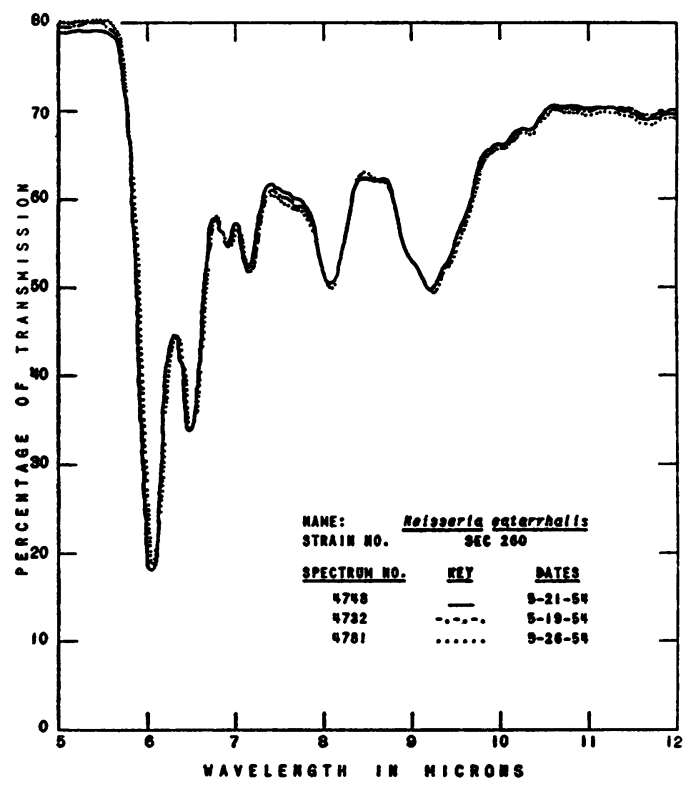

Figure \&

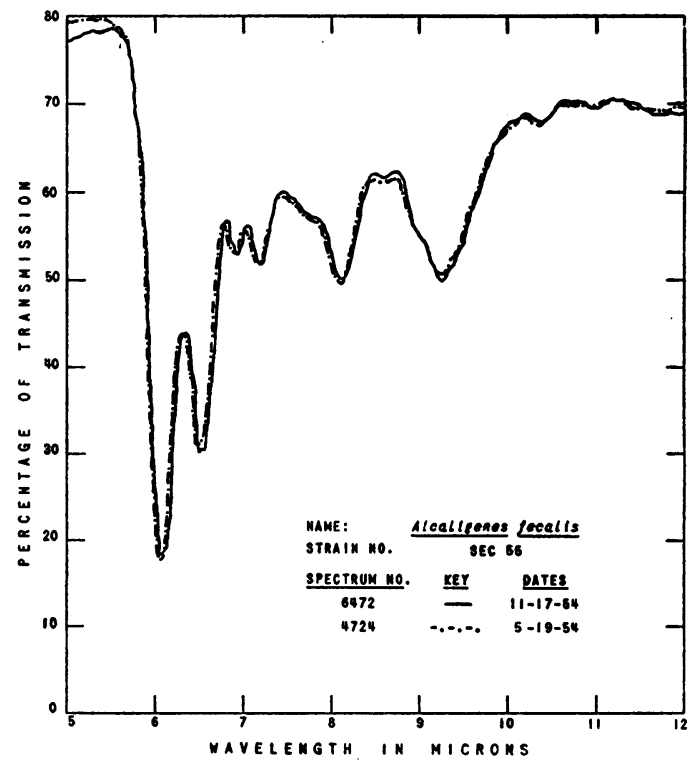

Figure $\mathrm{s}$ 


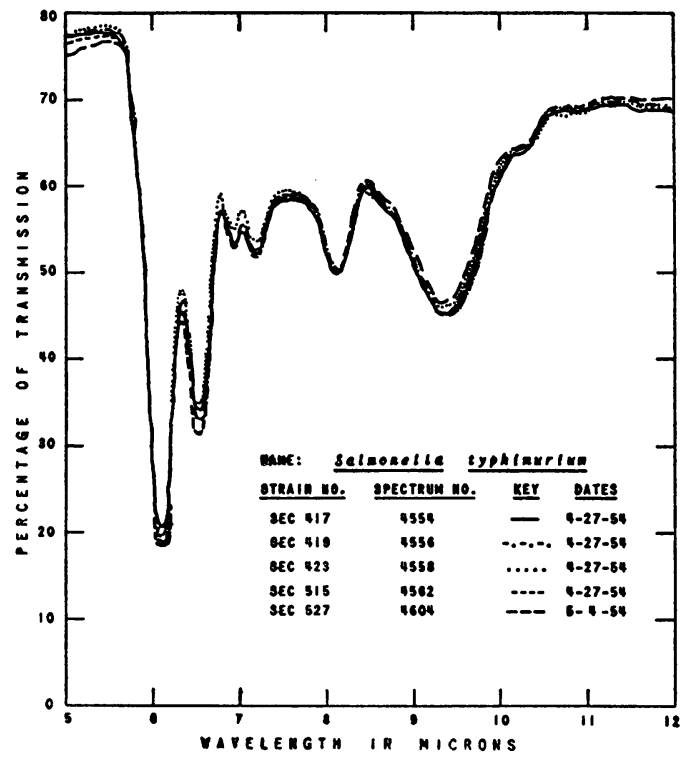

Figure \&

sections-each based on a fixed percentage - was devised. Figures 5 and 6 show the effect of adjustment on the spectra of the same strains of $B$. anthracis, and $N$. catarrhalis (figures 1 and 2, respectively).

From comparisons of the unadjusted and the adjusted spectra of the same strain or species, it is clear that these adjustments only alter slightly the longer vertical passages of the spectrum, and preserve entirely the specific locations and shapes of absorption maxima and minima which are characteristic of the spectrum.

Coding of spectra for punch cards. Early attempts to devise a coding system for use with punched cards concerned the locations of transmission and absorption peaks and shoulders. These proved to be inadequate. Experimentation showed, if points taken at intervals of $0.1 \mu$ along the spectrum were plotted and connected, that the characteristics of the entire infrared spectrum were reproduced with sufficient accuracy to insure superposition of the plotted spectrum and the original spectrum.

To provide a basis for a convenient and efficient coding system, tracings of 55 adjusted spectra of different strains of 10 dissimilar bacteria were superimposed. The resulting summary spectrum revealed that the major portion of a bacterial spectrum is likely to have adjusted transmittances between 50 and 60 per cent; small portions may fall between 50 and 40 per cent, and between 60 and 70 per cent. Because of these findings, the system of overpunches used in the coding procedure were adopted, in order that nearly all of the spectrum could be punched without overpunches and with only one digit per column. When overpunches are needed, only one is necessary except in two small regions of the spectrum totalling $0.5 \mu$.

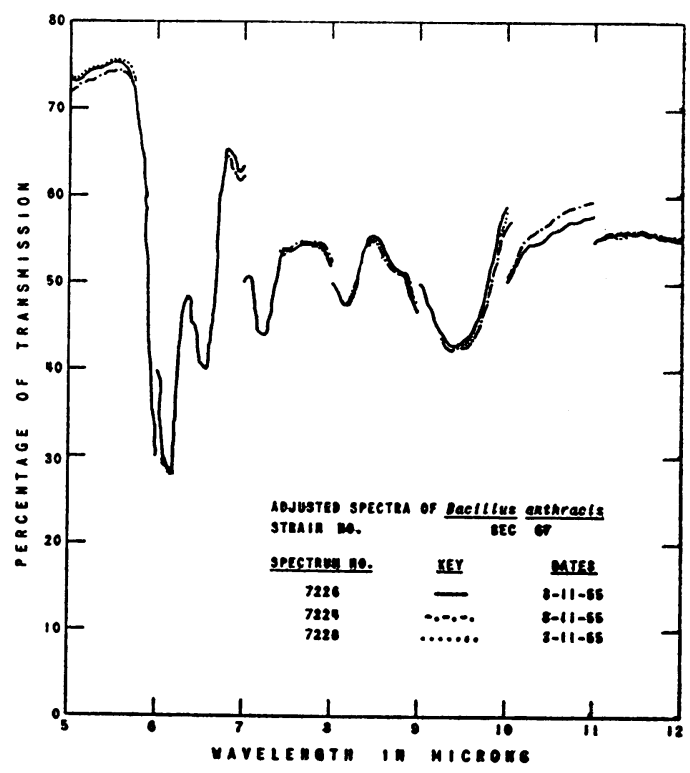

Figure 5

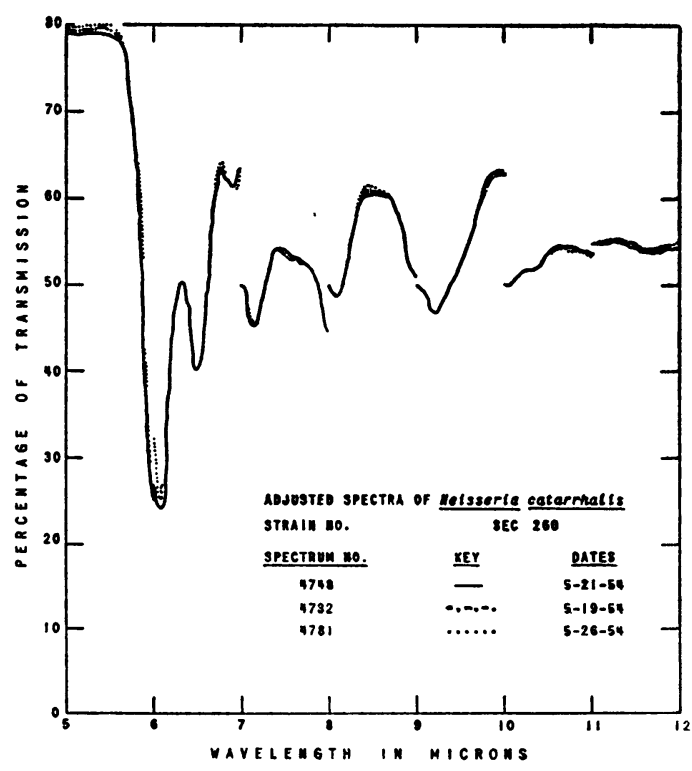

Figure 6 
This coding system permitted the rapid and easy recording of an infrared bacterial spectrum on a single punch card, along with the morphological and gram staining characteristics of the culture and identification numbers for spectra, cultures, media, and experiments.

Use of these codes has made the punched cards, and the electromechanical and electronic equipment available for handling them, a research tool whereby a large collection of standard infrared spectra of microorganisms and associated data may be subjected to rapid sorting, examination, and comparison.

Range in per cent infrared transmission among repeated spectra of different bacteria. Table 2 shows data derived from 54 spectra obtained in series from different bacteria at monthly intervals, and from 61 spectra of 10 different strains of $S$. typhimurium also made at monthly intervals. Although over that period of time films were prepared on different $\mathrm{AgCl}$ discs, and from different cultures of the same strains, the spectra were collected otherwise under identical conditions for each microorganism. Table 2 shows the ranges in per cent infrared transmission in each micron for the group of spectra of each species and strain throughout the spectrum $(7.0 \mu$ to $12.0 \mu)$.

Each of the two bacteria, Flavobacterium suaveolens and $N$. catarrhalis had a variation of 2 per cent or less throughout 98 per cent of the spectrum. When data from all 52 of the spectra of the 10 bacteria listed in the upper half of table 2 are considered together, there is an overall variation in reproducibility of 1 per cent or less throughout 54.9 per cent of the spectrum from $7.0 \mu$ to $12.0 \mu$, an overall variation of 2 per cent or less throughout 83.1 per cent of the spectrum, and an overall variation of 3 per cent or less throughout 94.7 per cent of the spectrum.

The range in per cent transmission in each micron between $7.0 \mu$ and $12.0 \mu$ is given in the lower half of table 2 for each of the 10 strains of S. typhimurium. Analysis of these data showed that variations of 2 per cent or less throughout the spectrum (7.0 to $12.0 \mu$ ) ranged from 98 per cent of the spectrum for the 5 spectra of strain SEC 429 , to 78 per cent of the spectrum for the 8 spectra of strain SEC 416. It is significant to note that 8 of the 10 strains had variations of 2 per cent or less throughout 84 per cent or more of the spectrum. When the data from the 10

TABLE 2

Maximum range in per cent infrared transmission per micron among repeated spectra of different bacteria

\begin{tabular}{|c|c|c|c|c|c|c|c|c|c|}
\hline $\begin{array}{c}\text { SEC } \\
\text { Strain } \\
\text { No. }\end{array}$ & Bacterial Species & $\begin{array}{l}\text { No. of } \\
\text { Spectra }\end{array}$ & $\begin{array}{l}7.0- \\
7.9 \mu\end{array}$ & $\begin{array}{l}8.0- \\
8.9 \mu\end{array}$ & $9.0-$ & $\begin{array}{l}10.0- \\
10.9_{\mu}\end{array}$ & $\begin{array}{l}11.0- \\
12.0_{\mu}\end{array}$ & $\underset{\text { range }}{\text { Maxi- }}$ & $\begin{array}{l}2 \text { Per cent or } \\
\text { Less Variation } \\
\text { from 7.0-12.0 } \\
\mu \text { Throughout }\end{array}$ \\
\hline & & & & & & & & & per cent \\
\hline 3 & Achromobacter liquefaciens & 6 & 5 & 3 & 3 & 3 & 3 & 5 & 75 \\
\hline 48 & Aerobacter aerogenes & 6 & 3 & 4 & 3 & 2 & 3 & 4 & 86 \\
\hline 55 & Alcaligenes & 6 & 1 & 4 & 2 & 2 & 2 & 4 & 92 \\
\hline 499 & Bacillus cereus & 6 & 4 & 6 & 3 & 5 & 2 & 6 & 57 \\
\hline 115 & Corynebacterium pyogenes & $\mathbf{5}$ & 3 & 3 & 3 & 2 & 4 & 4 & 82 \\
\hline 169 & Escherichia coli & 6 & 2 & 4 & 2 & 4 & 2 & 4 & 78 \\
\hline 175 & Flavobacterium suaveolens & 2 & 3 & 2 & 1 & 1 & 2 & 3 & 98 \\
\hline 202 & Leuconostoc dextranicum & 5 & 3 & 4 & 2 & 3 & 3 & 4 & 80 \\
\hline 225 & Micrococcus pyogenes var. albus & 6 & 3 & 5 & 3 & 2 & 2 & 5 & 80 \\
\hline 260 & Neisseria catarrhalis & 6 & 3 & 2 & 2 & 1 & 2 & 3 & 98 \\
\hline 416 & Salmonella typhimurium & 8 & 2 & 5 & 4 & 3 & 3 & 5 & 78 \\
\hline 417 & Salmonella typhimurium & 8 & 3 & 3 & 2 & 3 & 3 & 3 & 82 \\
\hline 418 & Salmonella typhimurium & 7 & 3 & 3 & 2 & 3 & 2 & 3 & 88 \\
\hline 419 & Salmonella typhimurium & 6 & 2 & 3 & 2 & 2 & 2 & 3 & 96 \\
\hline 420 & Salmonella typhimurium & 6 & 2 & 3 & 5 & 2 & 2 & 5 & 84 \\
\hline 429 & Salmonella typhimurium & 5 & 2 & 3 & 2 & 2 & 2 & 3 & 98 \\
\hline 511 & Salmonella typhimurium & 5 & 2 & 3 & 2 & 2 & 3 & 3 & 94 \\
\hline 513 & Salmonella typhimurium & 5 & 2 & 4 & 3 & 2 & 3 & 4 & 84 \\
\hline 514 & Salmonella typhimurium & 5 & 2 & 4 & 3 & 3 & 2 & 4 & 88 \\
\hline 515 & Salmonella typhimurium & 6 & 1 & 2 & 4 & 3 & 3 & 4 & 84 \\
\hline
\end{tabular}




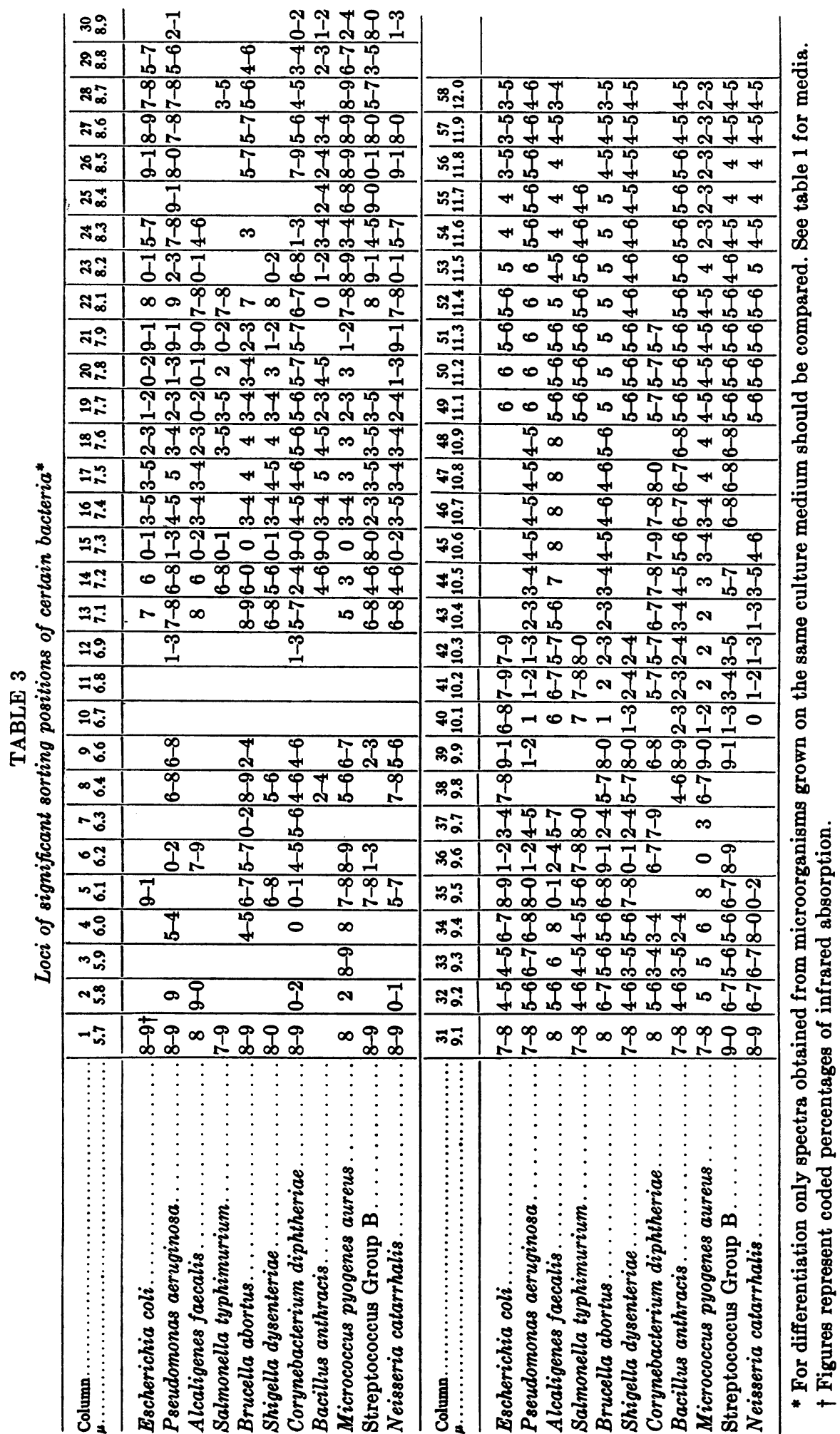


strains are pooled, they reveal that throughout the range from $7.0 \mu$ to $12.0 \mu$ the 61 spectra had an overall variation of one per cent or less in 50.8 per cent of the spectrum, a variation of 2 per cent or less in 88.1 per cent of the spectrum, and a variation of 3 per cent or less in 97.5 per cent of the spectrum.

Determination of differential characteristics in bacterial infrared spectra. The results of investigations on reproducibility of bacterial infrared spectra provided a firm basis for collecting a catalog of standard spectra of a wide variety of microorganisms. Consequently 1,395 spectra of 650 strains of 201 species of 33 genera have been collected. Of these 637 have been coded and punched into cards.

In order to determine the loci of specific spectral characteristics of a given species for possible use in microbial differentiation and identification, the punched cards of infrared spectra of all the strains of the particular species under consideration were passed through the sorter at each column (each $0.1 \mu$ ), and the distribution recorded. Only columns in which all cards fell out within 2 per cent were arbitrarily designated as being significant sorting positions. Samples of such data appear in table 3 . The numbers in the table indicate the percentages in which the cards agreed at each $0.1 \mu$ from $5.7 \mu$ to $12.0 \mu$.

By selecting one of the bacteria listed in table 3 and comparing it columnwise with other microorganisms, points of differentiation and similarity become evident. The information in table 3 reveals that certain wavelengths, for example, $6.1,6.2,6.4,6.6,8.3,9.6,9.7,10.2$, and 10.4 provide a wider base for differentiation among the gram negative rods than do the others. When organisms more widely separated taxonomically are compared, differences between the two are frequently of wider amplitude and at more numerous wavelengths.

Proposed procedure for identification of an unknown microorganism. The unknown microorganism should be inoculated onto plates of several different culture media, which have been used to grow bacteria for the standard identified spectra in the catalog. The unknown bacterium should be harvested from the medium (or media) which yielded the best growth. At the time of harvest for preparation of the sample film, a gram stain of the unknown should be made.
For comparison of the unknown, therefore, only these punched cards from the catalog should be used which contain spectra of organisms from the same staining and morphological categories, and which were grown on the same medium (or media) as the unknown. On the basis of its gram reaction and morphology, the unknown can usually be placed into one of the four well known categories: gram positive rods, gram positive cocci, gram negative rods, or gram negative cocci. Gram variable organisms and those with other morphological features are similarly provided for.

Cards of the appropriate category should be selected from the catalog and placed in the sorter. A series of sorts should be made in the columns in which differentiation is more apt to occur. When a given column is chosen, the machine is set to sort in that column and to select those cards which are punched within 2 per cent of the value in that same column of the unknown. For example, if in column 21 the unknown spectrum has a punch in the 3 position, then the known cards should be passed through the sorter selecting only those cards which have either a 2,3 , or 4 punched in column 21. From this group further sorts in the series are made in other columns in the same fashion until the identity of the unknown has been established.

Experiments performed to date have shown that identity has been established usually from a series of eight sorts.

\section{DISCUSSION}

The obvious qualitative differences in infrared spectra of various microorganisms suggested their possible usefulness in identification. However, the inability to obtain at will qualitatively and quantitatively reproducible spectra from different samples of the same culture, or from different cultures of the same microorganism, so far has prevented the use of infrared spectrophotometry in the identification of microorganisms, and has inhibited its use in the precise study of biological substances.

By controlling the conditions under which the bacteria are cultivated, by precise adjustments of the spectrophotometer, and by the use of sample films of controlled thickness, the variations in infrared spectra of different samples of the same bacterial culture were virtually eliminated. When these same techniques were applied to the col- 
lection of infrared spectra of different strains of a bacterial species, excellent reproducibility was achieved.

With many strains of certain species of bacteria spectra were either completely superimposible or very nearly so throughout the entire range from $5.8 \mu$ to $12.1 \mu$. The loci of absorption bands were identical; and the shapes of the absorption maxima and minima were identical or very nearly so. Small variations in the depths of the respective absorption bands were found to occur occasionally in spectra from different strains of the same species.

On the other hand, some species, notably Bacillus cereus, exhibited more variation among strains and hence had poorer reproducibility and coincidence of spectra. Similar observations concerning spectra from gram positive sporulating bacilli have been made by Bolduan and by Melvin and Haines (1954, personal communication).

The process of adjustment for coding purposes, of the various sections of the spectrum from constant values for each, enhanced the reproducibility of the spectra from cultures of the same bacterial strain, and minimized the differences between different strains of the same species. The same process also made less obvious the dissimilarities in transmission and absorption percentages between spectra of different species. Because significant differences between spectra of many species were still readily discernible, the coincidence of spectra of different strains of the same species outweighed the disadvantage of the difference-minimizing tendency.

Because reproducibility appeared to be best between $7.0 \mu$ and $12.1 \mu$, this portion of the spectrum was of most value in differentiation. If the remainder of the spectrum from $5.0 \mu$ to $7.0 \mu$ was analyzed a few additional points of differentiation were often found.

Since reproducibility is the key to the whole problem, the spectrophotometer performance must be controlled rigidly. This is most easily accomplished by comparisons of frequently repeated spectra of the standard polystyrene film, and by careful polishing and checking of the $\mathrm{AgCl}$ dises on which the sample films are placed. The culture media, incubation times and temperatures, and the techniques of harvesting the microbial samples must be kept constant also.
Experimental evidence supporting this view will be published elsewhere.

For valid differentiation, only spectra obtained from microorganisms grown on the same culture medium should be compared.

A large number of widely separate genera and species have been investigated, and results to date include the spectra of many strains; however, more strains of other species are being collected for study, in order to define the limits of variation to be accepted for each species.

The results indicate that many microorganisms have significant differences in their infrared spectra and that these can be used for purposes of identification. Certain strains and species of bacteria at present cannot be separated from each other by this type of analysis.

The coding system has proved to be simple, accurate, and successful in use with IBM cards and equipment. The electro-mechanical and electronic devices available offer rapid sorting, examination, and comparison of spectra and associated data from a large collection of standard spectra of microorganisms.

Ideally, the entire spectrum in the punched card of an unknown bacterium should be matched simultaneously against each individual known spectrum from the catalog of punched cards, with acceptable limits of variation. The electromechanical sorters cannot do this because it is possible for them to sort only one column $(0.1 \mu$ of an entire spectrum) at one time. Even at the conventional rates of either 250 or 450 cards per min, columnar comparisons of large numbers of cards would still be tedious and time consuming. It is possible, of course, to record in the "memory" of a large electronic computer the entire catalog of coded bacterial infrared spectra from the collection of punched cards. The functioning speed of such a device would enable comparisons of a coded unknown spectrum with the standard spectra at the rate of 20,000 to 32,000 operations per second.

When sufficient data have been accumulated, it will be possible to compile tables of significant wavelengths of coded spectra from each species, so that identifications could be made by direct comparisons between the unknown coded spectrum and tables of known spectra. Another type of comparison now being studied is based on successive superpositions of the punched card 
containing the adjusted unknown spectrum on punched cards containing the significant sorting positions derived from the adjusted summary spectra of all available strains of each species.

Since a high degree of reproducibility in infrared spectra of microorganisms is now possible, the differences which exist between the spectra of different genera and species of bacteria may be studied with greater precision, and may assume real significance not only in identification and clarification of taxonomic relationships, but also in studies of microbial metabolism. When varied appropriately, the techniques may also contribute to more accurate applications of infrared spectrophotometry in other areas of biological and biochemical investigation.

\section{SUMMARY}

Procedures have been developed for the standardization of bacterial infrared spectra which provide reproducibility of a very high order. A coding system has been devised which permits simple, rapid, and accurate recording of an entire bacterial infrared spectrum, together with all of the necessary identification data, in one punch card. By using these methods a total of 1,395 infrared spectra have been obtained in the study of 650 strains of 201 species of 33 genera of bacteria. Of these spectra 637 have been considered as standards and have been coded and punched into IBM cards, forming the nucleus of a catalog.

Comparisons of these standard infrared spectra indicate that many bacteria have significant differences in their infrared spectra which are characteristic. At the present time certain bacteria cannot be differentiated from each other by this type of analysis.

It is proposed that these infrared spectrophotometric methods will provide quantitatively and qualitatively more precise spectra which may be of value not only in the rapid identification of microorganisms, but also in investigations of other biological substances.

\section{REFERENCES}

Benedict, A. A. 1955 Group classification of virus preparations by infrared spectroscopy. J. Bacteriol., 69, 264-269.

Blout, E. R. ANd Mellors, R. D. 1949 Infrared spectra of tissues. Science, 110, 137-138.

Burket, S. C. and Melvin, E. H. 1952 An observation on the infrared absorption spectrum of dextran. Science, 115, 516-517.

Coblentz, W. W. 1911 Radiometric investigation of water of crystallization, light filters, and standard absorption bands. Bull. Natl. Bur. Standards (U. S.) 7, 619-663.

Kuentzes, L. E. 1951 New codes for Hollerithtype punched cards to sort infrared absorption and chemical structure data. Anal. Chem., 23, 1413-1418.

Levine, S. AND Stevenson, H. J. R. 1952 Infrared spectra of pneumococcal polysaccharides. Science, 116, 705-706.

Levine, S., Stevenson, H. J. R., ANd Bordner, R. H. 1953a Identification of glycogen in whole bacterial cells by infrared spectrophotometry. Science, 118, 141-142.

Levine, S., Stevenson, H. J. R., Chambers, L. A., AND KenNer, B. A. $1953 b$ Infrared spectrophotometry of enteric bacteria. J. Bacteriol., 65, 10-15.

Levine, S., Stevenson, H. J. R., and Kabler, P. W. 1953c Qualitative studies of pneumococcal polysaccharides by infrared spectrophotometry. Arch. Biochem. and Biophys., 45, 65-73.

Levine, S., Stevenson, H. J. R., Tabor, E. C., Bordner, R. H., and Chambers, L. A. 1953 Glycogen of enteric bacteria. J. Bacteriol., 66, 664-670.

MARTIN, A. E. 1952 Identification of organic compounds from infrared spectra. Nature, $170,20-22$.

Micks, D. W. ANd Benedict, A. A. 1953 Infrared spectrophotometry as a means for identification of mosquitoes. Proc. Soc. Exptl. Biol. Med., 84, 12-14.

Pollard, M., Engley, F. B., Jr., Redmond, R. F., Chinn, H. I., and Mitchell, R. B. 1952 Infrared absorption spectra of viruses. Proc. Soc. Exptl. Biol. Med., 84, 10-11.

Randali, H. M., Fowler, R. G., Fuson, N., AND DANGL, J. R. 1949 Infrared determination of organic structures. D. Van Nostrand Co., Inc., New York, N. Y.

Randale, H. M. and Smith, D. W. 1953 Infrared spectroscopy in bacteriological research. J. Opt. Soc. Amer., 43, 1086-1092.

Randale, H. M., Smith, D. W., Colm, A. C. and Nungester, W. J. 1951 Correlation of biologic properties of strains of Mycobacterium with infrared spectrum. Am. Rev. Tuberc. 63, 372-380.

Randali, H. M., Smith, D. W., and Nungester, W. J. 1952 Correlation of biologic properties of strains of Mycobacterium with their infrared spectrums. II. The differentiation of 
two strains H34Rv and H37Ra of $M$. tuberculosis by means of their infrared spectrums. Am. Rev. Tuberc., 65, 477-480.

Schwarz, H. P., Riggs, H. E., Glick, C., McGrath, J., Cameron, W., Beyer, E., Bew, E. Jr., ANd Childs, R. 1952 Infrared spectroscopy of brain tissue. A lipid fraction in normal and irradiated adult and fetal rats. Proc. Soc. Exptl. Biol. Med., 80, 467-472.

Schwarz, H. P., Riggs, H. E., Glick, C., Cameron, W., Beyer, E., Jaffe, B., and TromBETTA, L. 1951 Infrared spectroscopy of tissues. Effect of insulin shock. Proc. Soc. Exptl. Biol. Med., 76, 267-272.

Simon, S. ANd Hedrick, L. R. 1955 Infrared spectrophotometry of Hansenula and Saccharomyces whole yeast cells and yeast cellulose. J. Bacteriol., 69, 4-8.

Smith, D. W., Harrell, W. K., and Randall, H. M. 1954 Correlation of biologic prop- erties of strains of Mycobacterium with their infrared spectrums. III. Differentiation of bovine and human varieties of $M$. tuberculosis by means of their infrared spectrums. Am. Rev. Tuberc., 69, 505-510.

Stair, R. and Coblentz, W. W. 1935 Infrared absorption spectra of plant and animal tissue and of various other substances. J. Research Natl. Bur. Standards, 15, 295-316.

Stevenson, H. J. R. ANd Bolduan, O. E. A. 1952 Infrared spectrophotometry as a means for identification of bacteria. Science, 116, 111-113.

Thomas, L. C., Austin, L., and Davies, D. R. 1954 The examination of a nervous tissue by infrared spectrophotometry. Spectrochim. Acta, 6, 320-330.

Thomas, L. C. and Greenstreet, J. E. S. 1954 The identification of microrganisms by infrared spectrophotometry. Spectrochim. Acta, 6, 302-319. 